\title{
A Curve-Fitting Approach to Estimate the Arterial Plasma Input Function for the Assessment of Glucose Metabolic Rate and Response to Treatment
}

\author{
Dennis Vriens, Lioe-Fee de Geus-Oei, Wim J.G. Oyen, and Eric P. Visser \\ Department of Nuclear Medicine, Radboud University Nijmegen Medical Center, Nijmegen, The Netherlands
}

\begin{abstract}
For the quantification of dynamic ${ }^{18}$ F-FDG PET studies, the arterial plasma time-activity concentration curve (APTAC) needs to be available. This can be obtained using serial sampling of arterial blood or an image-derived input function (IDIF). Arterial sampling is invasive and often not feasible in practice; IDIFs are biased because of partial-volume effects and cannot be used when no large arterial blood pool is in the field of view. We propose a mathematic function, consisting of an initial linear rising activity concentration followed by a triexponential decay, to describe the APTAC. This function was fitted to 80 oncologic patients and verified for 40 different oncologic patients by areaunder-the-curve (AUC) comparison, Patlak glucose metabolic rate $\left(\mathrm{MR}_{\mathrm{glc}}\right)$ estimation, and therapy response monitoring
\end{abstract} $\left(\Delta \mathrm{MR}_{\mathrm{glc}}\right)$. The proposed function was compared with the gold standard (serial arterial sampling) and the IDIF. Methods: To determine the free parameters of the function, plasma time-activity curves based on arterial samples in 80 patients were fitted after normalization for administered activity (AA) and initial distribution volume (iDV) of ${ }^{18} \mathrm{~F}-\mathrm{FDG}$. The medians of these free parameters were used for the model. In 40 other patients ( 20 baseline and 20 follow-up dynamic ${ }^{18}$ F-FDG PET scans), this model was validated. The population-based curve, individually calibrated by $A A$ and iDV (APTAC $\left.{ }_{A A / i D V}\right)$, by 1 late arterial sample $\left(\right.$ APTAC $\left._{1 \text { sample }}\right)$, and by the individual IDIF (APTAC IDIF), was compared with the gold standard of serial arterial sampling (APTAC $_{\text {sampled }}$ ) using the AUC. Additionally, these 3 methods of APTAC determination were evaluated with Patlak $\mathrm{MR}_{\text {glc }}$ estimation and with $\Delta \mathrm{MR}_{\mathrm{glc}}$ for therapy effects using serial sampling as the gold standard. Results: Excellent individual fits to the function were derived with significantly different decay constants $(P<0.001)$. Correlations between AUC from APTAC $_{\text {AA/iDV }}$, APTAC $_{1 \text { sample, and APTAC }}$ IDIF with the gold stan-

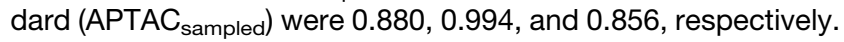
For $\mathrm{MR}_{\mathrm{glc}}$, these correlations were $0.963,0.994$, and 0.966 , respectively. In response monitoring, these correlations were $0.947,0.982$, and 0.949 , respectively. Additional scaling by 1 late arterial sample showed a significant improvement $(P<0.001)$. Conclusion: The fitted input function calibrated for AA and iDV performed similarly to IDIF. Performance im-

Received Apr. 18, 2009; revision accepted Aug. 28, 2009.

For correspondence or reprints contact: Dennis Vriens, Department of Nuclear Medicine, Radboud University Nijmegen Medical Center, P.O.

Box 9101, 6500 HB Nijmegen, The Netherlands.

E-mail: D.Vriens@nucmed.umcn.nl

COPYRIGHT $\odot 2009$ by the Society of Nuclear Medicine, Inc. proved significantly using 1 late arterial sample. The proposed model can be used when an IDIF is not available or when serial arterial sampling is not feasible.

Key Words: ${ }^{18}$ F-FDG; positron emission tomography; chemotherapy; therapy monitoring; input function; theoretical models; pharmacokinetics; body fluid compartments; least-squares analysis; tissue distribution

J Nucl Med 2009; 50:1933-1939

DOI: 10.2967/jnumed.109.065243

$\mathbf{P}$ harmacokinetic analysis of ${ }^{18} \mathrm{~F}-\mathrm{FDG}$ by dynamic PET requires both the arterial plasma time-activity concentration curve (APTAC, or $\mathrm{C}_{\mathrm{p}}(\mathrm{t})$ [input function]) and the tissue time-activity curve measured by PET (TTAC, or $\mathrm{C}_{\mathrm{T}}(\mathrm{t})$ ) to be available to create a Patlak plot $(l)\left(\frac{\mathrm{C}_{\mathrm{T}}(\mathrm{t})}{\mathrm{C}_{\mathrm{p}}(\mathrm{t})}\right.$ vs. $\left.\frac{\int_{0}^{t} \mathrm{C}_{\mathrm{p}}(\tau) \mathrm{d} \tau}{\mathrm{C}_{\mathrm{p}}(\mathrm{t})}\right)$, from which the glucose metabolic rate $\left(\mathrm{MR}_{\mathrm{glc}}\right)$ in the tissue of interest can be derived. Special interest in this type of quantitative analysis has risen for oncologic patients for prognostic stratification and response monitoring of disease.

The gold standard to obtain the APTAC is by measuring decay-corrected activity concentrations in plasma obtained by serial arterial sampling (2). This is an invasive and potentially harmful procedure for the patient and exposes the personnel to radiation. Complications attributed to radial artery cannulation include temporary occlusion $(19.7 \%)$ and hematoma formation (14.4\%), local infection $(0.72 \%)$, sepsis $(0.13 \%)$, permanent occlusion $(0.09 \%)$, and pseudoaneurysm $(0.09 \%)$ (3), some of which require medical intervention. Therefore, different methods have been developed to reduce these drawbacks. The major 4 alternatives to serial arterial sampling are (arterialized) venous blood sampling $(4,5)$, image-derived input function (IDIF) estimation (6-12), population-based input function (13-17) modeling, and whole-blood input function extraction using sophisticated mathematic image segmentation methods (i.e., cluster analysis (18) and independent component analysis (19-21)). 
A drawback of venous sampling is the time-dependent ratio of ${ }^{18} \mathrm{~F}-\mathrm{FDG}$ in venous to arterial blood (a ratio of $0.61-0.88$ at 5-50 $\mathrm{min}$ after injection) $(4,5)$. Therefore, shunting of arterial blood to the venous system (the heatedhand procedure) is used to improve these ratios to 0.92 1.05 (4). This arterialized venous sampling technique still requires cannulation of an extra vein and exposes personnel to radiation.

IDIFs require a large blood pool (aorta, left ventricle) within the field of view of the PET image. IDIFs show systematic error, because activity concentration is measured in whole blood, and activity concentration is known to be lower in whole blood than in plasma (ratio, 0.925-0.95) (6-8). Moreover, partial-volume effects cause inaccuracy by spillover of activity from or to the surrounding tissues (e.g., myocardium) (6,9). Finally, additional noise is introduced because of the limited number of counts in the short early time frames. Because underestimation due to spill-out of the IDIF activity concentration leads to overestimation of $\mathrm{MR}_{\mathrm{glc}}$ and overestimation due to spill-in of surrounding IDIF activity concentration (in later time frames) leads to underestimation of $\mathrm{MR}_{\mathrm{glc}}(6,9)$, correction is necessary (10-12).

A population-based APTAC is based on the averaging of normalized sampled blood data of multiple patients. Several corrections were introduced, based on administered activity (AA), body weight, and blood transit time (13) or AA and body surface area $(14,15)$. The latter provided a reliable estimation of $\mathrm{MR}_{\mathrm{glc}}$ but yielded less accurate parameter values in pharmacokinetic analysis. Another method is the fitting of the sampled data to an equation, assuming the ${ }^{18} \mathrm{~F}$-FDG distribution in the vascular system as a compartment model on its own $(16,17,22)$.
Here, we describe an APTAC model that is based on the fitting of a large series of arterially sampled oncologic patients to a mathematic equation $(16,17,22)$. The model APTAC was calibrated to individual patients of a separate patient population by either an estimation of the distribution volume of ${ }^{18} \mathrm{~F}$-FDG $(14,15)$ or 1 late arterial blood sample and compared with the gold standard of arterial sampling and the IDIF. The performance of both models was assessed by comparison of the APTACs themselves and by their influence on Patlak $\mathrm{MR}_{\mathrm{glc}}$ and therapy response $\left(\Delta \mathrm{MR}_{\mathrm{glc}}\right)$ evaluation.

\section{MATERIALS AND METHODS}

\section{Patient Population, Arterial Sampling Procedure}

Data of 120 dynamic ${ }^{18} \mathrm{~F}$-FDG PET scans with serial arterial sampling data were reanalyzed. Scans were randomly distributed over 2 groups (Table 1): a parameter-identification group $(n=80)$ and a parameter-validation group $(n=40)$. For the latter group, both a pretreatment and a follow-up scan, after 2-3 courses of chemotherapy, were included. The details of ${ }^{18}$ F-FDG PET and arterial plasma data acquisition are described elsewhere (9), with the only difference being that they were reconstructed using ordered-subsets expectation maximization with 4 iterations and 16 subsets with a gaussian filter of $5 \mathrm{~mm}$ in all directions. In short, normoglycemic patients who had fasted were injected with ${ }^{18} \mathrm{~F}-$ FDG by an automated standardized infusion protocol. Directly thereafter, 17 arterial blood samples were taken at set time points from which plasma was obtained by centrifugation to provide a sampled arterial plasma time-activity concentration curve (APTAC sampled $_{\text {). Simultaneously, dynamic PET, consisting of } 16}$ time frames of variable length, was performed to provide both the tissue (TTAC) and the image-derived blood time-activity concentration curves $\left(\mathrm{APTAC}_{\mathrm{IDIF}}\right)$.

TABLE 1. Comparison Between Parameter-Identification and Parameter-Validation Groups, with Statistical Significance of Group Difference

\begin{tabular}{|c|c|c|c|}
\hline Parameter & Identification & Validation & $P$ \\
\hline PET scans (individual patients) & $80(49)$ & $40(20)$ & $0.327^{*}$ \\
\hline Male sex (\% of scans) & 60 & 70 & $0.320^{*}$ \\
\hline Age (y) & & & $0.225^{\dagger}$ \\
\hline Median & 60.7 & 60.1 & \\
\hline Range & $44.8-78.9$ & $44.7-71.9$ & \\
\hline Mean administered activity $\pm \mathrm{SD}(\mathrm{MBq})$ & $207 \pm 40.1$ & $200 \pm 35.8$ & $0.314^{\ddagger}$ \\
\hline Plasma glucose concentration $\left(\mathrm{mmol} \cdot \mathrm{L}^{-1}\right)$ & & & $0.125^{\dagger}$ \\
\hline Median & 5.3 & 5.3 & \\
\hline Range & $4.2-10.0$ & $4.2-8.3$ & \\
\hline $\mathrm{BMI}\left(\mathrm{kg} \cdot \mathrm{m}^{-2}\right)$ & & & $0.508^{\dagger}$ \\
\hline Median & 25.8 & 25.9 & \\
\hline Range & $22.7-27.4$ & $19.8-33.7$ & \\
\hline Cancer localization (\% of scans) & & & $0.618^{*}$ \\
\hline Lung (non-small cell) & 50 & 50 & \\
\hline Colorectal & 45 & 40 & \\
\hline Breast & 5 & 10 & \\
\hline $\begin{array}{l}{ }^{*} \chi^{2} \text { test. } \\
{ }^{\dagger} \text { Mann-Whitney } U \text { test. } \\
{ }^{\ddagger} \text { Independent-samples } t \text { test. } \\
\text { BMI = body mass index. }\end{array}$ & & & \\
\hline
\end{tabular}


Parameter-Identification Study $(n=80)$

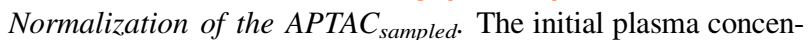
tration of ${ }^{18} \mathrm{~F}-\mathrm{FDG}\left(\mathrm{C}_{\mathrm{p}} *(0)\left[\mathrm{MBq} \cdot \mathrm{L}^{-1}\right]\right)$ was used to normalize the

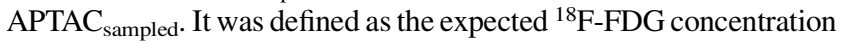
directly after tracer injection, assuming instant homogenization, and is dependent on the $\mathrm{AA}(\mathrm{MBq})$ and the (apparent) initial distribution volume (iDV, $[\mathrm{L}])(14,15)$. To avoid confusion, an "*” is added, because the sampled activity concentration at $\mathrm{t}=0$ is $0 \mathrm{MBq} \cdot \mathrm{L}^{-1}$.

In the period between 5 and 30 min after injection, the plasma and extravascular extracellular ${ }^{18} \mathrm{~F}-\mathrm{FDG}$ pool of the whole body were assumed to be in equilibrium (23). Before this period, the tracer is being distributed over the body, and in the period thereafter, the tracer is mainly being metabolized and excreted. Within this interval, we sampled 4 times $(7.5,12.5,17.5$, and 25 min after injection) (9) to obtain $\mathrm{C}_{\mathrm{p}} *(0)$; semilogarithmic recordings of these 4 points were linearly extrapolated back to $\mathrm{t}=0$ (y-intercept) $(15,23)$.

Estimation of iDV by Body Weight and Height. By definition, the iDV represents the (virtual) volume of the plasma and extravascular extracellular ${ }^{18}$ F-FDG pool. The iDV can be estimated by $(14,15)$ :

$$
\mathrm{iDV}=\frac{\mathrm{AA}}{\mathrm{C}_{\mathrm{p}}^{*}(0)}=\mathrm{c} \cdot \mathrm{H}^{\mathrm{h}} \cdot \mathrm{W}^{\mathrm{w}}
$$

where $\mathrm{H}$ is patient height $(\mathrm{m})$ and $\mathrm{W}$ is patient body weight $(\mathrm{kg})$. Iteratively $\mathrm{h}, \mathrm{w}$, and $\mathrm{c}$ were derived for which the coefficient of variation of $\mathrm{c}\left(\mathrm{CV}_{\mathrm{c}}=\frac{\mathrm{SD}_{\mathrm{c}}}{\text { mean }_{\mathrm{c}}}\right)$ is smallest in the parameter-identification data.

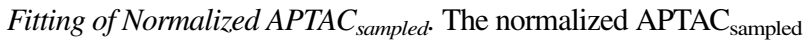
can be approximated using the 3-compartment model for the blood pool as proposed by Feng et al. (16), simplified by Eberl et al. (17), as the following:

$$
\frac{\operatorname{APTAC}_{\text {sampled }}(\mathrm{t})}{\mathrm{C}_{\mathrm{p}}^{*}(0)}=\left\{\begin{array}{cc}
\mathrm{t}<-\frac{\mathrm{b}}{\mathrm{a}} & \\
\mathrm{a} \cdot \mathrm{t}+\mathrm{b} & -\frac{\mathrm{b}}{\mathrm{a}} \leq \mathrm{t}<\tau \\
\sum_{\mathrm{i}=1}^{3} \mathrm{~A}_{\mathrm{i}} \cdot \mathrm{e}^{-\lambda_{\mathrm{i}} \cdot(\mathrm{t}-\tau)} & t \geq \tau
\end{array} \quad\right. \text { Eq. 2 }
$$

where $\tau$ is the time to peak activity concentration. The normalized sampled plasma curves were fitted by linear curve fitting $(t<\tau)$ and by nonlinear least squares $(t \geq \tau)$ to obtain the 8 free parameters in every patient of the parameter-identification study. Because chemotherapy might influence ${ }^{18} \mathrm{~F}$-FDG distribution and clearance, the parameter values were compared between scans made in patients who did and did not receive chemotherapy.

\section{Parameter-Validation Study $(n=40)$}

IDIF and Tumor Time-Activity Curves. The APTAC $\mathrm{IDIF}_{\mathrm{IF}}$ was determined in manually placed volumes of interest (VOIs) over the ascending aorta (thoracic images) or descending aorta (abdominal images) known to correlate best with the gold standard (9) on summed images of the period 30-90 s after injection. The TTAC was obtained semiautomatically by placing volumes of interest in the summed images of the period 20-50 min after injection over the largest lesion, fully present in the field of view, using a threshold of $50 \%$ of its maximum voxel value. All images were analyzed using the Inveon Research Workplace (version 2.2; Siemens).
Comparison of Calibrated Plasma Time-Activity Curves and Glucose Metabolic Rates. Median values of APTAC parameters derived from the parameter-identification study were used for the population-based APTAC, which was calibrated to each individual patient, using 2 methods: by either multiplication by AA (MBq) divided by iDV (L) (estimated using Eq. 1, further mentioned as $\left.\mathrm{APTAC}_{\mathrm{AA} / \mathrm{iDV}}\right)$ or multiplication by the plasma activity concentration of 1 late arterial sample (APTAC sample $_{\text {s }}$ ).

The performance of the 3 curves $\left(\mathrm{APTAC}_{\mathrm{AA} / \mathrm{iDV}}, \mathrm{APTAC}_{1 \text { sample, }}\right.$ and $\left.\mathrm{APTAC}_{\mathrm{IDIF}}\right)$ was compared with that of the gold standard $\left(\right.$ APTAC $\left._{\text {sampled }}\right)$ by their area under the curve (AUC), determined by trapezoid integration.

$\mathrm{MR}_{\text {glc }}$ was determined using all 4 plasma input curves by Patlak graphical analysis (1). In the Patlak approximation, the lumped constant, accounting for the difference in glucose and ${ }^{18} \mathrm{~F}$ FDG affinity, was set to 1 and the tumor blood fraction was set to 0 . Therefore, the slope of the Patlak plot was $K_{i}$ and the intercept was $\frac{K_{1} \cdot k_{2}}{\left(k_{2}+k_{3}\right)^{2}}$. MR $\mathrm{Mlc}_{\mathrm{glc}}$ can then be determined by multiplying the linear regression (5-50 min after injection) by the plasma glucose concentration.

\section{Statistical Analysis}

All variables were assessed for normality (Shapiro-Wilk, skewness, and kurtosis) and are either displayed as mean ( \pm SD) or median (interquartile range). Comparison between 2 independent groups was performed by the $t$ test, the Mann-Whitney $U$ test, or the $\chi^{2}$ test. $\lambda_{1}-\lambda_{3}$ were compared using Friedman ANOVA. Correlations between the AUC, $\mathrm{MR}_{\mathrm{glc}}$, and $\Delta \mathrm{MR}_{\mathrm{glc}}$ of the different curves compared with the gold standard were assessed by Pearson $r$ or Spearman $\rho$ and linear regression and are displayed as Bland-Altman plots. Confidence intervals for correlation coefficients were compared after Fisher $z$ transformation (24). Analysis was performed by SPSS 16.0.2 (SPSS Inc.). Twosided significance was set at the 0.050 level.

\section{RESULTS}

\section{Parameter-Identification Study}

A median iDV of $12.7 \mathrm{~L}$ (corresponding to $0.1683 \mathrm{~L} / \mathrm{kg}$ body weight) was calculated. Iterative determination of the function to estimate the iDV led to $\mathrm{h}=1.257, \mathrm{w}=0.582$, and $\mathrm{c}=0.533 \mathrm{~L} \cdot \mathrm{m}^{-1.257} \cdot \mathrm{kg}^{-0.582}$ (minimum $\mathrm{CV}_{\mathrm{c}}, 0.171$; adjusted $R^{2}, 0.3181$ ).

Fitting of the 80 APTAC $_{\text {sampled }}$ by Equation 2 led to a minimum adjusted $R^{2}$ of $0.8533 ; 80 \%$ of fits had an adjusted $R^{2}$ greater than 0.9500 . Resulting parameters for

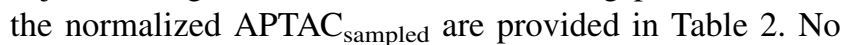
significant difference in ${ }^{18} \mathrm{~F}-\mathrm{FDG}$ clearance could be detected $(P>0.326)$ between patients who did and did not receive chemotherapy. The 3 decay constants $\left(\lambda_{1}-\lambda_{3}\right)$ were significantly different $(P<0.001$; Fig. 1$)$.

\section{Parameter-Validation Study}

The correlation between the AUC of the APTAC $\mathrm{AA} / \mathrm{iDV}$ and the $\mathrm{APTAC}_{\text {sampled }}$ was 0.880 . This correlation improved to $0.994(P<0.001)$ using 1 arterial sample for calibration. The mean AUC of $\mathrm{APTAC}_{\mathrm{AA} / \mathrm{iDV}}$ was similar to (462 $\left.\pm 119 \mathrm{MBq} \cdot \mathrm{L}^{-1} \cdot \mathrm{min}\right)$, and that of $\mathrm{APTAC}_{1 \text { sample }}$ slightly lower than $\left(468 \pm 107 \mathrm{MBq} \cdot \mathrm{L}^{-1} \cdot \mathrm{min}\right)$, the gold standard $\left(\mathrm{APTAC}_{\text {sampled }}, 475 \pm 108 \mathrm{MBq} \cdot \mathrm{L}^{-1} \cdot \mathrm{min}\right.$, 
TABLE 2. Results of Fitting of Normalized Plasma Data of Parameter-Identification Group and Subgroup Analysis Between Pretherapy Scans and Posttherapy Scans

\begin{tabular}{|c|c|c|c|c|c|c|c|}
\hline \multirow[b]{2}{*}{ Parameter } & \multicolumn{2}{|c|}{ All scans $(n=80)$} & \multicolumn{2}{|c|}{ Pretherapy scans $(n=40)$} & \multicolumn{2}{|c|}{ Follow-up scans $(n=40)$} & \multirow[b]{2}{*}{$P^{*}$} \\
\hline & Median & IQR & Median & IQR & Median & IQR & \\
\hline$\tau(\min )$ & 1.25 & $1.25-1.50$ & 1.25 & $1.25-1.25$ & 1.25 & $1.25-1.50$ & 0.077 \\
\hline $\mathrm{a}\left(\min ^{-1}\right)$ & 4.911 & $4.188-5.709$ & 4.914 & $4.154-5.660$ & 4.911 & $4.203-5.771$ & 0.672 \\
\hline b & -2.077 & -2.817 to -1.321 & -1.195 & -2.805 to -1.096 & -2.225 & -2.961 to -1.503 & 0.168 \\
\hline$A_{1}$ & 2.785 & $2.302-3.212$ & 2.718 & $2.241-3.152$ & 2.937 & $2.321-3.300$ & 0.326 \\
\hline$\lambda_{1}\left(\min ^{-1}\right)$ & 6.133 & $4.646-8.114$ & 6.034 & $4.121-8.064$ & 6.133 & $4.833-8.322$ & 0.622 \\
\hline $\mathrm{A}_{2}$ & 0.7085 & $0.6492-0.8011$ & 0.6966 & $0.6340-0.8434$ & 0.7229 & $0.6694-0.8130$ & 0.589 \\
\hline$\lambda_{2}\left(\min ^{-1}\right)$ & 0.2541 & $0.2075-0.3071$ & 0.2400 & $0.1881-0.3423$ & 0.2592 & $0.2285-0.2847$ & 0.805 \\
\hline $\mathrm{A}_{3}$ & 0.7721 & $0.7177-0.8070$ & 0.7699 & $0.6861-0.8286$ & 0.7741 & $0.7385-0.7970$ & 0.920 \\
\hline$\lambda_{3}\left(\min ^{-1}\right)$ & 0.01443 & $0.01248-0.01595$ & 0.01446 & $0.01206-0.01656$ & 0.01434 & $0.01260-0.01590$ & 0.562 \\
\hline
\end{tabular}

$P=0.156$ and $P<0.001$, respectively). The $\mathrm{APTAC}_{\mathrm{IDIF}}$ showed much lower AUCs than APTAC sampled $_{\text {(3) }} \pm 99$ $\mathrm{MBq} \cdot \mathrm{L}^{-1} \cdot \min , P<0.001$ ), with a correlation coefficient between these parameters of 0.856 .

Comparison between $\mathrm{MR}_{\mathrm{glc}}$ is shown in Figure 2 (left panels). Adding 1 arterial sample (25 min after injection) improved the correlation between $\mathrm{MR}_{\mathrm{glc}}$, determined by APTAC $_{\mathrm{AA} / \mathrm{iDV}}$ and $\mathrm{APTAC}_{\text {sampled }}$, from $\rho=0.963$ to $\rho=$ $0.994(P<0.001)$. MR $_{\mathrm{glc}}$ determined by IDIF was significantly higher than the gold standard; the correlation was similar to that of $\operatorname{APTAC}_{\mathrm{AA} / \mathrm{DDV}}(\rho=0.966)$.

Comparison between therapy effects $\left(\Delta \mathrm{MR}_{\mathrm{glc}}\right)$ is shown in Figure 2 (right panels). Adding 1 arterial sample (25 min after injection) improved the correlation between $\Delta \mathrm{MR}_{\mathrm{glc}}$ determined by $\mathrm{APTAC}_{\mathrm{AA} / \mathrm{iDV}}$ and $\mathrm{APTAC}_{\text {sampled }}$ from $\rho=$

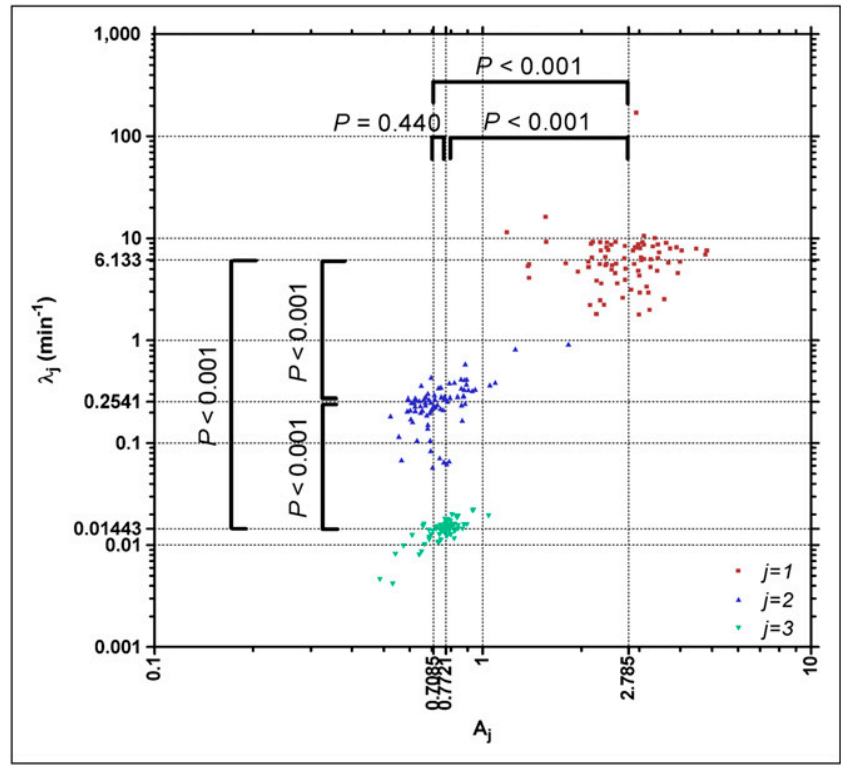

FIGURE 1. Scatter plot of $\log _{10}\left(A_{j}\right)$ vs. $\log _{10}\left(\lambda_{j}\right)$, showing clustering of 3 decay constants.
0.947 to $\rho=0.982(P=0.012)$. $\Delta \mathrm{MR}_{\text {glc }}$ determined by APTAC $_{\text {IDIF }}$ had a correlation to the gold standard similar to that determined by $\operatorname{APTAC}_{\mathrm{AA} / \mathrm{iDV}}(\rho=0.949)$.

Any arterial sample taken at $7.5 \mathrm{~min}$ after injection showed similar high correlations when comparing $\operatorname{MR}_{\text {glc }}(\rho \geq 0.9916)$ or $\Delta \mathrm{MR}_{\mathrm{glc}}(\rho \geq 0.9759)$ measured by APTAC sampled $_{\text {and }}$ APTAC $_{1 \text { sample. }}$.

\section{DISCUSSION}

This study describes the performance of a populationbased APTAC based on fitting patient data to a mathematic equation on Patlak determination of $\mathrm{MR}_{\mathrm{glc}}$ and on chemotherapy response evaluation. Its accuracy is comparable to that of an IDIF, explaining 93\% of variance in $\mathrm{MR}_{\mathrm{glc}}(90 \%$ in response evaluation by $\Delta \mathrm{MR}_{\mathrm{glc}}$ ), but the addition of 1 late arterial sample improves this to $99 \%$ (96\% in response evaluation by $\Delta \mathrm{MR}_{\mathrm{glc}}$ ). Where the IDIF is fully individual, the proposed method is a population average, calibrated to individual patient parameters without the need for serial arterial sampling. The method can be used when scanning body regions where blood pools are unavailable, such as the extremities. The model can be further improved by including 1 arterial sample. It can be expected that a late arterialized venous sample might adequately replace the arterial sample, because more than approximately $30 \mathrm{~min}$ after ${ }^{18} \mathrm{~F}$-FDG injection, activity concentrations of arterial and arterialized venous blood are highly similar $(4,5)$. This sample might also be used to obtain an accurate measurement of the plasma glucose level, as long as radiation safety regulations do not prohibit this analysis in the clinical chemistry laboratory. As shown, $\mathrm{MR}_{\mathrm{glc}}$ was significantly overestimated using an IDIF, compared with the gold standard. Both the partial-volume effect and the fact that whole-blood activity concentrations are lower than in plasma cause underestimation of the (integral of the) APTAC. From the Patlak equation it can be derived that an underestimation of the APTAC and its integral cause overestimation of the $\mathrm{MR}_{\mathrm{glc}}$. The quality of the IDIF can be 

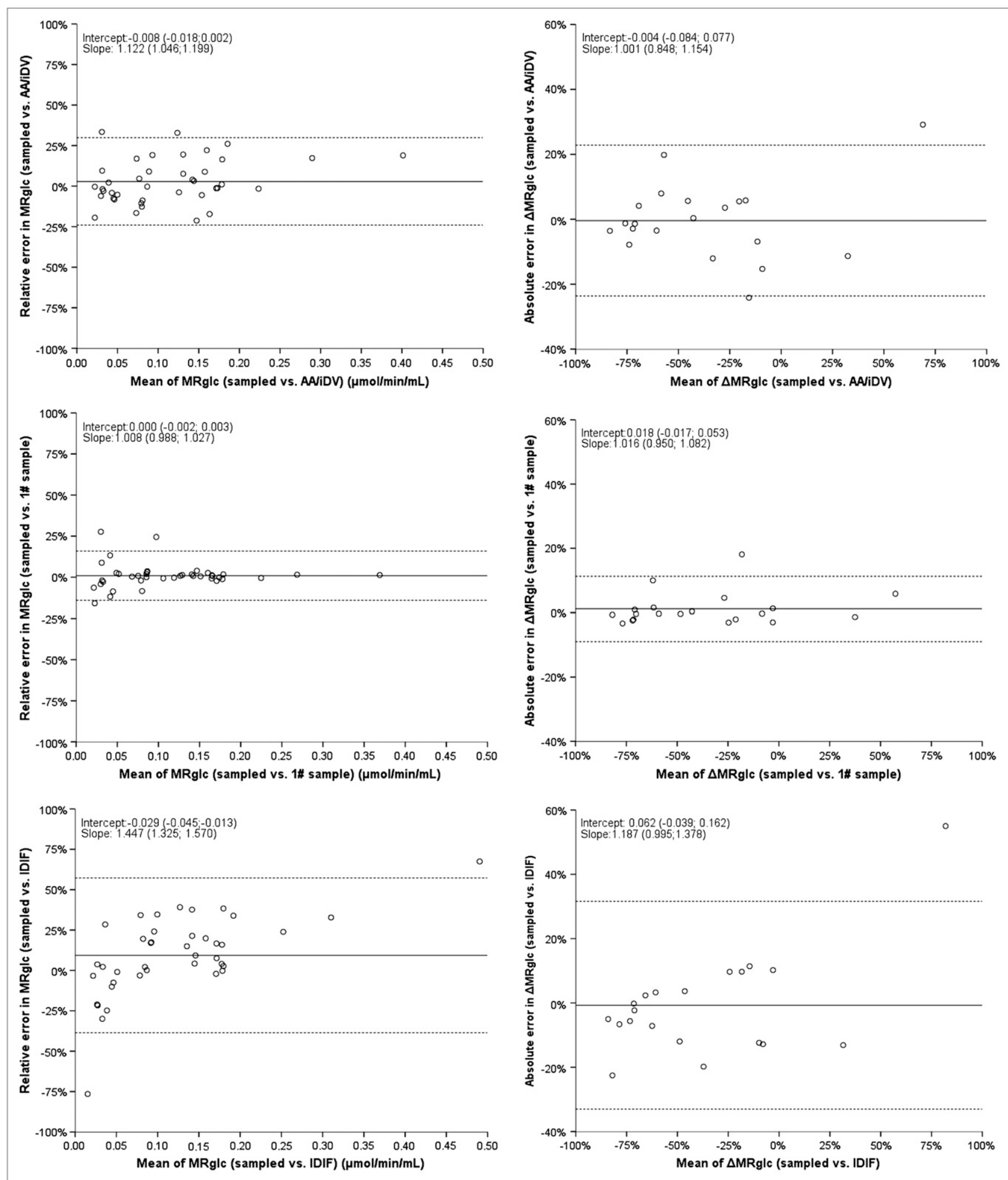

FIGURE 2. Bland-Altman plots of comparison between any of 3 evaluated APTACs and gold standard. In Bland-Altman plots, mean difference is displayed by solid line and $95 \%$ confidence interval by dotted lines. Unstandardized regression coefficients are displayed with corresponding $95 \%$ confidence interval. 1\# sample was calibrated by 1 arterial sample at 25 min after injection; AA/iDV was calibrated by AA and iDV. 
improved by correction for the partial-volume and spillover effects (25). Moreover, the activity in whole blood can be corrected to the activity concentration in plasma using hematocrit (19) or modeled erythrocyte uptake (26). In addition, the noise in the short early time frames contributes to the inaccuracy of the activity concentration. Recently, 8 methods for the estimation of the carotid IDIF in human brain studies were compared with the reference input function (arterially sampled) with respect to cerebral $\mathrm{MR}_{\mathrm{glc}}$ and individual rate constants in a study consisting of phantoms and healthy volunteers. The authors concluded that blood-sample-free methods provided less reliable results than those obtained using the methods that require blood samples, even when limited to a single sample (27). Therefore, calibration of our IDIFs by 1 late venous sample would probably have improved the accuracy of these IDIFs. The advantage of a more patient-specific rather than a generic input function is especially important for pharmacokinetic analysis, because the exact shape of the APTAC in the artery feeding the tumor is vital and is usually different from a remote artery (because of delay and dispersion by the intraindividual variation in the impulseresponse characteristics of the vascular system).

One method of calibration of the population-based curve was by the approach of Sadato et al. (23) (AA/iDV). They reported a mean iDV scaled to body weight (iDV ${ }_{\mathrm{BW}}$ ) of $0.1627 \mathrm{~L} \cdot \mathrm{kg}^{-1}$, similar to this study (median $\mathrm{iDV}_{\mathrm{BW}}$ of $0.1683 \mathrm{~L} \cdot \mathrm{kg}^{-1}$ ). Around $50 \%-60 \%$ of the body weight of an average adult is water, of which $25 \%-45 \%(0.18$ $\mathrm{L} \cdot \mathrm{kg}^{-1}$ ) is extracellular fluid (the volume of water in which ${ }^{18}$ F-FDG dissolves), stressing both the concordance and plausibility of this result (28). We used the function of Shiozaki et al. (15) to fit the iDV. They reported an $\mathrm{iDV}[\mathrm{mL}]$ that equaled $39.0 \cdot \mathrm{H}[\mathrm{cm}]^{0.80} \cdot \mathrm{W}[\mathrm{kg}]^{0.35}$. This result appears different from the present study (iDV[L] = $\left.0.533 \cdot \mathrm{H}[\mathrm{m}]^{1.257} \cdot \mathrm{W}[\mathrm{kg}]^{0.582}\right)$, but they were only slightly off our optimum $\left(\mathrm{CV}_{\mathrm{c}}=0.18\right.$ vs. $\left.\mathrm{CV}_{\mathrm{c}}=0.17\right)$. A dissimilar distribution of body habitus in their (Asian) population might be the cause for this difference.
As shown in Figure 2, the difference between $\mathrm{MR}_{\mathrm{glc}}$ calculated by APTAC $_{1 \text { sample }}$ and APTAC $_{\text {sampled }}$ was small; therefore, the net influx constant determined by Patlak analysis was accurate. For determining the individual rate constants, however, the inaccuracy will probably be much higher. For Patlak analysis, only the integral of the APTAC and the late $(>5 \mathrm{~min})$ activity concentrations of the arterial plasma are relevant, but for the accurate estimation of the individual rate constants of glucose pharmacokinetics, the exact shape of the APTAC is vital, because of both the function (including a convolution operation) and the method for parameter estimation (nonlinear least squares). The delay and dispersion between the APTAC in the artery feeding the tissue of interest and a remote artery are of major importance for the accurate determination of the fast rate constants $\left(K_{1}\right.$ and $\left.k_{2}\right)$ and blood fraction $\left(\mathrm{V}_{\mathrm{b}}\right)$. Moreover, the use of a generic input function for pharmacokinetic analysis should be considered because of the large intraindividual variation of the slow clearance rate constants of ${ }^{18} \mathrm{~F}-\mathrm{FDG}\left(\lambda_{3}\right.$ [and to a lesser extent in $\lambda_{2}$ ] in Fig. 1 and Table 2). The assumption of a single clearance profile for all patients might therefore lead to the inaccurate estimation of the slower rate constants $\left(k_{3}\right.$ and, if it exists, $k_{4}$ ) of individual patients.

The proposed model, therefore, should be evaluated further for estimating microparameters before implementation. This further evaluation, however, was out of the scope of this study.

None of the previously published articles on populationbased input curves used an IDIF for comparison, and most studies consisted of a small series of nononcologic patients, but reproducibility was high (Table 3 ). The studies that used triexponential clearance of ${ }^{18} \mathrm{~F}-\mathrm{FDG}$ as a function for the APTAC $(16,17,22)$ found a decay similar to that found in this study (Fig. 3). The results shown in Figure 1 suggest a high (linear) correlation between $A_{3}$ and $\lambda_{3}$. This correlation suggests that the model might be simplified by omitting 1 parameter; we did not verify the possibility of simplifying the model in this study.

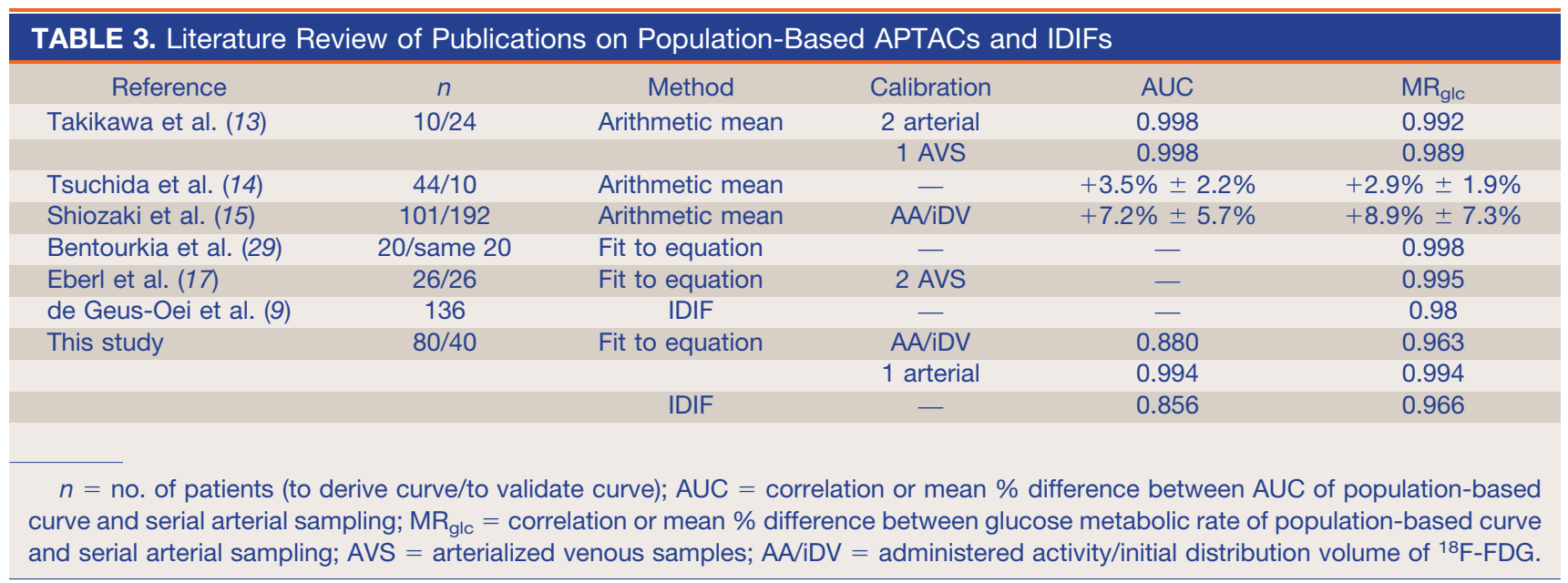




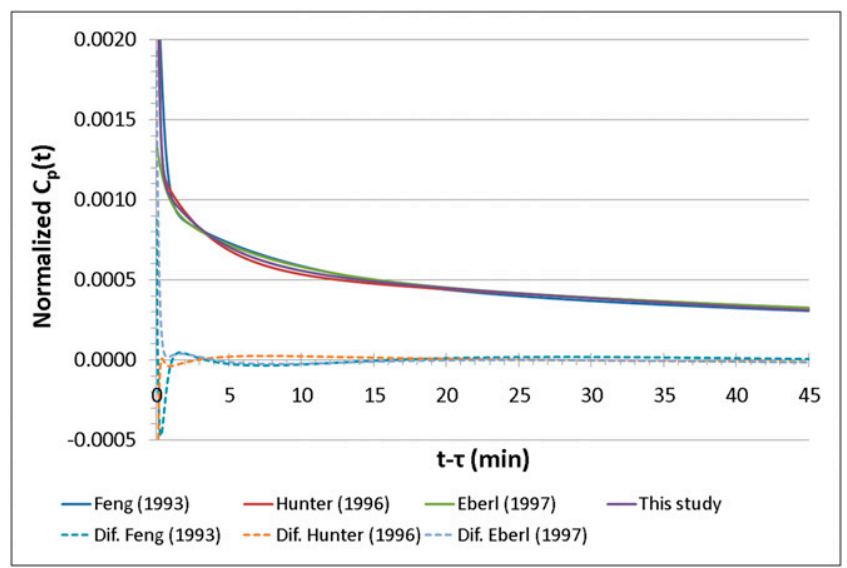

FIGURE 3. Comparison of triexponential ${ }^{18} \mathrm{~F}-\mathrm{FDG}$ clearance in our study and 3 previous publications $(16,17,22)$. Functions were normalized to total AUC. Dif. = absolute differences of our clearance curve compared with 3 found in literature.

\section{CONCLUSION}

The current model of the APTAC of ${ }^{18}$ F-FDG, calibrated by 1 late arterial sample, shows high accuracy for Patlak $\mathrm{MR}_{\mathrm{glc}}$ calculation and treatment response monitoring. The model allows dynamic scanning of areas without large vessels in the field of view, such as the extremities; is less invasive; and causes less radiation exposure to personnel than does arterial sampling. Even without a calibrating sample available, this model has the same accuracy as an IDIF, without its inherent disadvantages.

\section{REFERENCES}

1. Patlak CS, Blasberg RG, Fenstermacher JD. Graphical evaluation of blood-tobrain transfer constants from multiple-time uptake data. J Cereb Blood Flow Metab. 1983;3:1-7.

2. Greuter HN, Boellaard R, van Lingen A, Franssen EJ, Lammertsma AA. Measurement of ${ }^{18} \mathrm{~F}-\mathrm{FDG}$ concentrations in blood samples: comparison of direct calibration and standard solution methods. J Nucl Med Technol. 2003;31:206-209.

3. Scheer B, Perel A, Pfeiffer UJ. Clinical review: complications and risk factors of peripheral arterial catheters used for haemodynamic monitoring in anaesthesia and intensive care medicine. Crit Care. 2002;6:199-204.

4. van der Weerdt AP, Klein LJ, Visser CA, Visser FC, Lammertsma AA. Use of arterialised venous instead of arterial blood for measurement of myocardial glucose metabolism during euglycaemic-hyperinsulinaemic clamping. Eur $J$ Nucl Med Mol Imaging. 2002;29:663-669.

5. Wakita K, Imahori Y, Ido T, et al. Simplification for measuring input function of FDG PET: investigation of 1-point blood sampling method. J Nucl Med. 2000;41:1484-1490.

6. van der Weerdt AP, Klein LJ, Boellaard R, Visser CA, Visser FC, Lammertsma AA. Image-derived input functions for determination of MRGlu in cardiac ${ }^{18} \mathrm{~F}$ FDG PET scans. $J$ Nucl Med. 2001;42:1622-1629.

7. Dhawan V, Takikawa S, Robeson W, et al. Quantitative brain FDG/PET studies using dynamic aortic imaging. Phys Med Biol. 1994;39:1475-1487.

8. Ohtake T, Kosaka N, Watanabe T, et al. Noninvasive method to obtain input function for measuring tissue glucose utilization of thoracic and abdominal organs. J Nucl Med. 1991;32:1432-1438.
9. de Geus-Oei LF, Visser EP, Krabbe PF, et al. Comparison of image-derived and arterial input functions for estimating the rate of glucose metabolism in therapymonitoring ${ }^{18}$ F-FDG PET studies. J Nucl Med. 2006;47:945-949.

10. Lin KP, Huang SC, Choi Y, Brunken RC, Schelbert HR, Phelps ME. Correction of spillover radioactivities for estimation of the blood time-activity curve from the imaged LV chamber in cardiac dynamic FDG PET studies. Phys Med Biol. 1995;40:629-642.

11. Gambhir SS, Schwaiger M, Huang SC, et al. Simple noninvasive quantification method for measuring myocardial glucose utilization in humans employing positron emission tomography and fluorine-18 deoxyglucose. J Nucl Med. 1989;30:359-366.

12. Chen K, Bandy D, Reiman E, et al. Noninvasive quantification of the cerebral metabolic rate for glucose using positron emission tomography, ${ }^{18} \mathrm{~F}$-fluoro-2deoxyglucose, the Patlak method, and an image-derived input function. J Cereb Blood Flow Metab. 1998;18:716-723.

13. Takikawa S, Dhawan V, Spetsieris $P$, et al. Noninvasive quantitative fluorodeoxyglucose PET studies with an estimated input function derived from a population-based arterial blood curve. Radiology. 1993;188:131-136.

14. Tsuchida T, Sadato N, Yonekura Y, et al. Noninvasive measurement of cerebral metabolic rate of glucose using standardized input function. $J$ Nucl Med. 1999;40:1441-1445.

15. Shiozaki T, Sadato N, Senda M, et al. Noninvasive estimation of FDG input function for quantification of cerebral metabolic rate of glucose: optimization and multicenter evaluation. J Nucl Med. 2000;41:1612-1618.

16. Feng D, Huang SC, Wang X. Models for computer simulation studies of input functions for tracer kinetic modeling with positron emission tomography. Int $J$ Biomed Comput. 1993;32:95-110.

17. Eberl S, Anayat AR, Fulton RR, Hooper PK, Fulham MJ. Evaluation of two population-based input functions for quantitative neurological FDG PET studies. Eur J Nucl Med. 1997;24:299-304.

18. Liptrot M, Adams KH, Martiny L, et al. Cluster analysis in kinetic modelling of the brain: a noninvasive alternative to arterial sampling. Neuroimage. 2004;21: 483-493.

19. Su KH, Wu LC, Liu RS, Wang SJ, Chen JC. Quantification method in $\left[{ }^{18} \mathrm{~F}\right]$ fluorodeoxyglucose brain positron emission tomography using independent component analysis. Nucl Med Commun. 2005;26:995-1004.

20. Naganawa M, Kimura Y, Ishii K, Oda K, Ishiwata K, Matani A. Extraction of a plasma time-activity curve from dynamic brain PET images based on independent component analysis. IEEE Trans Biomed Eng. 2005;52:201-210.

21. Chen K, Chen X, Renaut R, et al. Characterization of the image-derived carotid artery input function using independent component analysis for the quantitation of $\left[{ }^{18} \mathrm{~F}\right]$ fluorodeoxyglucose positron emission tomography images. Phys Med Biol. 2007;52:7055-7071.

22. Hunter GJ, Hamberg LM, Alpert NM, Choi NC, Fischman AJ. Simplified measurement of deoxyglucose utilization rate. J Nucl Med. 1996;37: 950-955.

23. Sadato N, Tsuchida T, Nakaumra S, et al. Non-invasive estimation of the net influx constant using the standardized uptake value for quantification of FDG uptake of tumours. Eur J Nucl Med. 1998;25:559-564.

24. Fisher RA. On the 'probable error' of a coefficient of correlation deduced from a small sample. Metron. 1921;1:3-32.

25. Fang YH, Muzic RF Jr. Spillover and partial-volume correction for imagederived input functions for small-animal ${ }^{18} \mathrm{~F}$-FDG PET studies. $\mathrm{J}$ Nucl Med. 2008;49:606-614

26. Lee JS, Su KH, Lin JC, et al. A novel blood-cell-two-compartment model for transferring a whole blood time activity curve to plasma in rodents. Comput Methods Programs Biomed. 2008;92:299-304.

27. Zanotti-Fregonara P, Fadaili EM, Maroy R, et al. Comparison of eight methods for the estimation of the image-derived input function in dynamic $\left[{ }^{18} \mathrm{~F}\right]-\mathrm{FDG}$ PET human brain studies. J Cereb Blood Flow Metab. July 8, 2009 [Epub ahead of print].

28. Singer GG, Brenner BM. Chapter 46. Fluid and electrolyte disturbances. In: Fauci AS, Braunwald E, Kasper DL, et al., eds. Harrison's Principles of Internal Medicine. 17th ed. Columbus, OH: McGraw-Hill Companies; 2008:274-285.

29. Bentourkia M, Bol A, Ivanoiu A, et al. A standardized blood sampling scheme in quantitative FDG-PET studies. IEEE Trans Med Imaging. 1999;18: 379-384. 